\title{
Viewpoint
}

\section{Engaging Patients in Care (EPIC): A Framework for Heart Function and Heart Transplant-Specific Patient Engagement}

\author{
Jillian A Macklin, MSc, ${ }^{a}$ Natalie Djihanian, BCom, ${ }^{b}$ Tieghan Killackey, RN, MN, ${ }^{c, d}$ and \\ Jane MacIver, $\mathrm{RN}, \mathrm{PhD}^{\mathrm{c}, \mathrm{d}}$ \\ ${ }^{a}$ Faculty of Medicine, University of Toronto, Toronto, Ontario, Canada \\ ${ }^{b}$ Co-Chair HeartLinks, Patient Support Group, Toronto, Ontario, Canada \\ ${ }^{c}$ Ted Rogers Center for Heart Research and Peter Munk Cardiac Center, University Health Network, Toronto, Ontario, Canada \\ ${ }^{d}$ Lawrence S. Bloomberg Faculty of Nursing, University of Toronto, Toronto, Ontario, Canada
}

\begin{abstract}
Engaging Patients in Care (EPIC) is a local patient engagement initiative at the University Health Network for patients and families who have received care for heart failure, heart transplant, or mechanical circulatory support (left ventricular assist device). Patients and caregivers can engage at 4 different levels, including sharing, consulting, deliberating, and collaborating, depending on their knowledge, experience, and available time. The Engaging Patients In Care framework has 4 priority areas: Care Delivery and Policy, Patient Advocacy, Peer Support, and Research. We have identified key engagement barriers with a discussion of possible solutions. We hope this framework can be adapted as an evidentiary baseline for other heart failure and transplant institutions across Canada.
\end{abstract}

Heart failure (HF) is a leading cause of morbidity and mortality in Canada. ${ }^{1}$ The Canadian Cardiovascular Society has developed clinical guidelines and knowledge translation tools to inform the care of patients living with HF. However, the voices of patients with HF have remained largely absent from the local and national conversation. ${ }^{1}$ Comprehensive patient-centered care is important to clinicians, patients, and families. However, how do we deliver patientcentered care if they have not been included in the design,

Received for publication December 19, 2018. Accepted January 14, 2019.

Ethics Statement: The research reported has adhered to the relevant ethical guidelines.

Corresponding author: Dr Jane MacIver, Toronto General Hospital 6N-632, 200 Elizabeth St, Toronto, Ontario M5G 2C4, Canada. Tel.: +1-416-340-4622.

E-mail: Jane.maciver@uhn.ca

See page 46 for disclosure information.

\section{RÉSUMÉ}

Engaging Patients in Care (EPIC) est une initiative locale de participation des patients du University Health Network pour les patients et les familles qui ont reçu des soins en lien avec l'insuffisance cardiaque, la transplantation du cœur ou l'assistance circulatoire mécanique (dispositif d'assistance ventriculaire gauche). Les patients et les soignants peuvent participer à 4 niveaux différents, à savoir le partage, la consultation, la délibération et la collaboration, selon leurs connaissances, leur expérience et leur disponibilité. Le cadre EPIC comporte 4 volets prioritaires : la prestation de soins et les politiques, la défense des droits des patients, le soutien aux pairs et la recherche. Nous avons déterminé les principaux obstacles à la participation par un échange sur les solutions possibles. Nous espérons que ce cadre peut servir de référence en matière de preuves à d'autres établissements offrant des soins aux patients atteints d'insuffisance cardiaque et la transplantation du Canada.

delivery, and evaluation of care? A patient engagement framework supports patients, caregivers, and clinicians working together at various levels across programs, organizations, or systems. Patient engagement has been reported to keep patients more informed, improve clinical health outcomes, decrease hospital admissions, increase patient quality of life, improve safety, increase patient social community, and improve healthcare costs. ${ }^{2-7}$

This article highlights the purpose and goals of Engaging Patients in Care (EPIC), a local patient engagement initiative at University Health Network (UHN) for patients and families who have received care for HF, heart transplant (HT), or mechanical circulatory support (left ventricular assist device [LVAD]). It presents our levels and priorities of engagement, and identifies key engagement barriers with a discussion of possible solutions. We hope this framework can be adapted as an evidentiary baseline for other HF and HT institutions across Canada. 


\section{EPIC's Purpose and Goals}

The purpose of EPIC is to provide a mechanism that supports patients and caregivers who have experienced HF, HT, or LVAD implantation to partner with the UHN at various levels across the heart function and HT programs. We have adapted guiding principles for patient engagement from the Strategy for Patient-Oriented Research: ${ }^{8}$ Respect, Support, Transparency, Responsiveness, Fairness of Opportunity, and Accountability (descriptions are shown in Supplemental Table S1). These guiding principles match the values of UHN Patient Partners, a broader patient engagement network of which we are part. ${ }^{9}$ To ensure the patient and caregiver perspective is included in our mandate, we will determine terms of reference and meeting schedules after group membership has been determined.

\section{Levels of Engagement}

Patient engagement frameworks are often presented using a ladder format, with the higher rungs representing a greater degree of participation and more influence on decisionmaking. ${ }^{3}$ We chose to label our 4 levels of engagement as SHARE (patients and care providers exchange information for better understanding, ie, storytelling), CONSULT (care providers receive feedback from patients on a specific issue, ie, survey), DELIBERATE (patients engage to discuss issues and explore solutions with care providers, ie, focus group), and COLLABORATE (patients and care providers apply solutions together as leaders, ie, advisory committee), adapted from Health Quality Ontario's framework. ${ }^{10}$ We chose the first engagement level to be "share" instead of "inform" because informing represents unidirectional flow of information from one group to another, whereas sharing includes bidirectional exchange. Participants can choose where they want to engage on the basis of their knowledge, perspectives, values, interests, and available time. No level is more important than the other.

\section{Priorities of Engagement}

EPIC's 4 engagement priorities are (1) care delivery/policy, (2) patient advocacy, (3) research, and (4) peer support work (Fig. 1). We omitted direct care as a priority because it remains between the individual patient and his/her healthcare team. Peer-to-peer support recognizes the importance of information and mentorship from a community that has lived what you are currently living.

\section{Barriers and Solutions to Patient Engagement}

Discussed next are identified barriers with possible solutions to effective patient engagement, including representation, training/resources, tokenism, compensation, maintaining participation, and evaluation (Table 1).

\section{Representation}

Patient engagement can be challenging because it can exclude the very real complexities and context of peoples' lives that intersect in intricate and multifactorial ways. Those who often carry the greatest burden of illness, or those inhabiting a vulnerable space in society, are poorly represented on operational committees or health research. In the context of $\mathrm{HF}$, cardiovascular disease mortality in Canada is highest among those in lower-income groups, and as income increases, mortality rate decreases. ${ }^{3}$ It is important that the voices of this diverse population are represented during engagement activities. Some other examples include racial/ethnic minorities, the lesbian, gay, bisexual, transgender, queer (LGBTQ) community, the indigenous population, low literacy groups, or those who live in rural settings.

We recognize representation will be an ongoing issue moving forward. At the beginning of patient recruitment, it may realistically include convenience sampling, but upon program development, we will work to break down accessibility barriers. Of note, all participants will be trained to work effectively in a group and will be empowered to use their voice. Table 1 shows ways to increase representation. $3,11,12$

\section{Training and resources}

Proper training is essential for effective patient engagement. Patients recruited to EPIC will participate in the UHN Patient Partners Orientation Program to ensure compliance with institutional policies regarding confidentiality, communication,

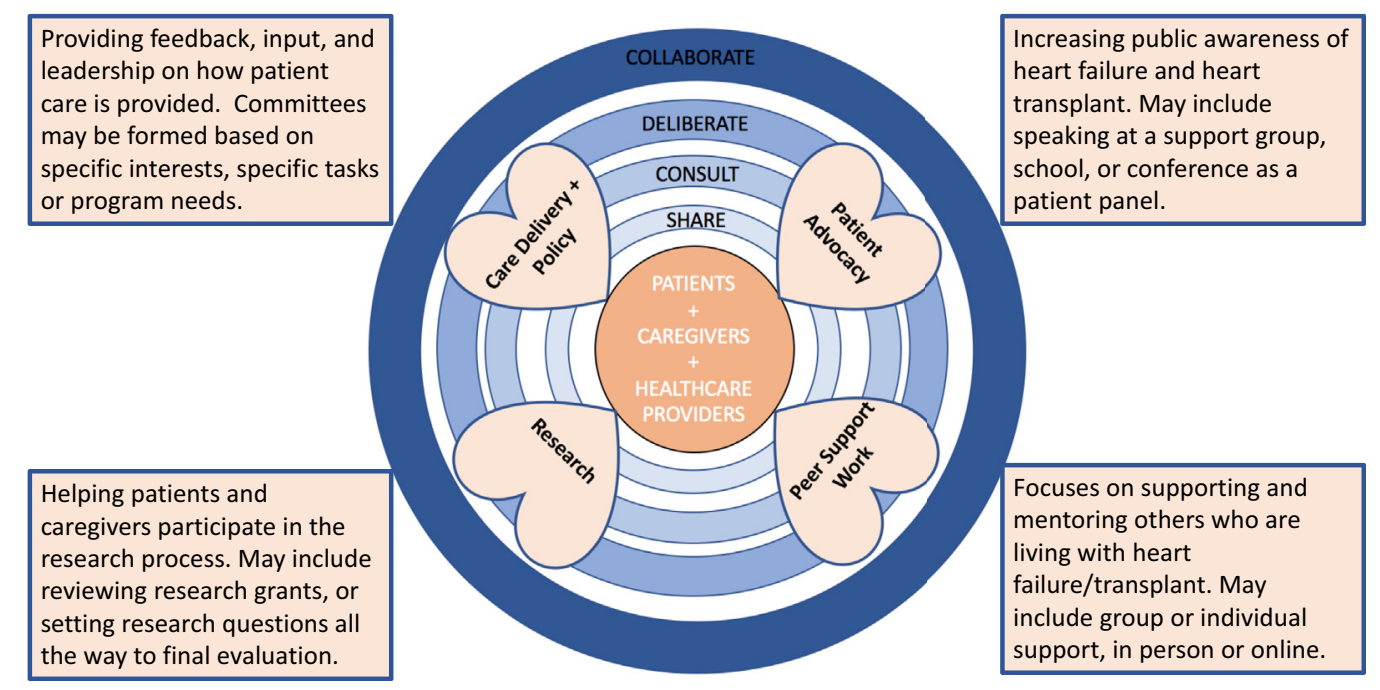

Figure 1. Engaging Patients in Care (EPIC)'s 4 priorities and levels of engagement. 


\begin{tabular}{|c|c|}
\hline Barrier & Potential solution \\
\hline Representation & $\begin{array}{l}\text { - Widen the recruitment process by partnering with community agencies, such as religious groups or refugee } \\
\text { organizations. } \\
\text { - Offer virtual/online options for those who live far, such as Zoom video conferencing. } \\
\text { - Offer language translation services. } \\
\text { - Do not overuse the caregiver for patients with disabilities - they still have a voice! } \\
\text { - Patients do not need to have had a good healthcare experience to be involved-instead of turning away patients who are } \\
\text { angry, we should help them come to terms with anger to be able to be engaged. } \\
\text { - Use a trauma-informed approach and actively resist re-traumatization. }{ }^{11} \\
\text { - Use different recruitment tactics for different age populations - children may enjoy creative media projects but elders } \\
\text { - may want to focus on gaining a social circle. } \\
\text { - Create a diversity working group, adapted from INVOLVE. } \\
\text { and employment/income. }\end{array}$ \\
\hline Training/resources & $\begin{array}{l}\text { - Use organizational programs to on-board patient and caregiver partners and conduct institutional privacy/ } \\
\text { confidentiality training. } \\
\text { - Use reflection tools about patients' strengths and areas to improve. } \\
\text { - Identify/develop specific modules for each engagement priority. } \\
\text { - Verbal material should be supplemented with written information. } \\
\text { - Provide access to online training and virtual tools. } \\
\text { - Identify a Staff and Patient Liaison for each engagement priority. } \\
\text { - Develop participant "champions" to teach new participants new skills. } \\
\text { - Provide patient engagement training and education for care providers to learn how to confidently work with the } \\
\text { public. }\end{array}$ \\
\hline Tokenism (false sense of inclusion) & $\begin{array}{l}\text { - For each project, the health provider(s) must clearly be able to answer the following } 5 \text { questions: (1) What aspect or } \\
\text { activity calls for a patient? (2) How will the patient engage? (3) What is the patient's role? (4) How will the patient be } \\
\text { prepared to engage? (5) Who will be the patient's support? } \\
\text { - At the beginning of each project, remind the group that not all patient input may be used or implemented. } \\
\text { - Send frequent reminders of appreciation highlighting patient value. }\end{array}$ \\
\hline Compensation & $\begin{array}{l}\text { - Reimburse all out-of-pocket expenses. } \\
\text { - Confirm compensation will not affect disability payments or tax returns. } \\
\text { the Change Foundation). }\end{array}$ \\
\hline $\begin{array}{l}\text { Maintaining patient/caregiver } \\
\text { participation }\end{array}$ & $\begin{array}{l}\text { - At the beginning of each project, establish a timeline for the project, as well as meeting dates/times. } \\
\text { - Maintain timeline and meeting schedule. } \\
\text { - Provide access to online webinars for meetings. } \\
\text { - Offer a variety of short- and long-term tasks within each project. }\end{array}$ \\
\hline Evaluation & $\begin{array}{l}\text { - Develop an evaluation tool for use across all projects (eg, McMaster's Public and Patient Engagement Evaluation } \\
\text { Tool). }{ }^{16} \\
\text { - Staff and Patient Liaison to check in with participants and debrief as needed. }\end{array}$ \\
\hline
\end{tabular}

and conflict resolution. Clinicians and researchers also may require training to ensure effective participation of patients and caregivers on operational or research committees. The care provider must clearly outline how the patient will be prepared and engaged to avoid tokenistic participation (Table 1).

We will determine the needs of all participants before developing specific training modules as to avoid assumption. We anticipate training will include written, didactic, and webbased resources from established patient-engagement programs such as the International Association for Public Participation. ${ }^{13}$ Because UHN cares for patients from all over Ontario, it is crucial to have materials housed on an electronic bulletin board so participants can access and review information when it suits their schedule from afar.

Training materials not covered by existing resources will be created by our team. Supplemental Figure S1 highlights anticipated training modules for EPIC's 4 engagement priorities. The Research engagement priority will be the biggest challenge for which care providers may hold skepticism, and the least baseline knowledge/training may be currently available. Adapting modules from the Centre of Excellence on Partnership with Patients and the Public will be a helpful start. ${ }^{14}$

A staff liaison will be appointed for each engagement priority to act as a consistent and dedicated support to help participants fully integrate into their engagement experience. We will also identify a participant liaison for each priority who can be approached for issues participants may not feel comfortable addressing with the staff liaison.

\section{Compensation}

Paying participants for their time can blur the distinction between volunteer vs employee. Compensation may also affect participants' monthly disability payments or tax returns. Multiple calculation tools have been developed to help determine compensation for engagement work, including factors such as time and equity. ${ }^{19}$ Although we agree with these factors, the cost exceeds our current budget. For now, EPIC will follow the standard to reimburse patients for eligible out-of-pocket expenses, such as parking, mileage, and accommodation. Video conferencing will be used to facilitate the participation of those who live far away from our center. The staff liaison position is in the portfolio of a graduate student or employee, and payment is part of their salaried employment. When the program grows, we plan to have a separate, paid staff liaison funded by a research grant from Ted Rogers Heart Research Centre of Excellence. 


\section{Evaluation}

Few organizations have formally assessed patients' experience or satisfaction after their engagement endeavour. McMaster's Public and Patient Engagement Evaluation Tool (PPEET), the purpose of which is to obtain participants' assessments of the key features of patient engagement initiatives, either as a 1-time initiative or ongoing long-term participation, will be used for evaluation. ${ }^{6}$ PPEET includes background information and a series of agree/disagree statements regarding engagement facets: communication, support, view sharing, satisfaction, and improvement. ${ }^{16}$ Although primarily developed for research engagement initiatives, PPEET is relevant for all 4 of EPIC's engagement priorities. We will not remove any questions from PPEET to ensure consistency across institutions. We have the option to add supplemental questions to reflect unique features of our clinical, advocacy, or mentorship priorities. A large question is whether EPIC will improve patient outcomes and patient care. This will not be evaluated through PPEET, but rather through a mixedmethods research study, including focus groups and interviewing when engagement projects are under way.

\section{EPIC's Goals}

This article is an early introduction to EPIC to start the conversation about patient engagement in HF, and we want to highlight our program goals.

In the short term, we will pilot EPIC with a small group of HT recipients at Toronto General Hospital. We will get them involved through orientation and training, create a terms of reference, use the online bulletin board, and complete the specific task of updating the hospital's HT manual with their lived experience within the Care Delivery/Policy engagement priority. We will have ongoing recruitment to EPIC and create and update training modules as we gain participant need or feedback.

Within intermediate time length, we will implement the PPEET $^{16}$ to the first participant cohort to improve EPIC accordingly and perform the first mixed-methods research study to evaluate the benefit of EPIC on each of the 4 engagement priorities. In the long term, our goal is to make patient engagement a standard of care in the HF community.

\section{Conclusion}

EPIC is a program-specific patient engagement framework for our HF, HT, and LVAD programs. We hope that this engagement framework can be used and adapted by other HF and HT programs in Canada. Patient engagement is multifaceted and presents many barriers that challenge our ability to be inclusive. We welcome comments and suggestions for our work from patients, families, and care providers.

\section{Disclosures}

The authors have no conflicts of interest to disclose.

\section{References}

1. Virani SA, Bains M, Code J, et al. The need for heart failure advocacy in Canada. Can J Cardiol 2017;33:1450-4.
2. Carman KL, Dardess P, Maurer M, et al. Patient and family engagement: a framework for understanding the elements and developing interventions and policies. Health Aff (Millwood) 2013;32:223-31.

3. Shimmin C, Wittmeier KDM, Lavoie JG, Wicklund ED, Sibley KM. Moving towards a more inclusive patient and public involvement in health research paradigm: the incorporation of a trauma-informed intersectional analysis. BMC Health Serv Res 2017;17:539.

4. Coulter A. Effectiveness of strategies for informing, educating, and involving patients. BMJ 2007;335:24-7.

5. Boivin A, Lehoux P, Lacombe R, Burgers J, Grol R. Involving patients in setting priorities for healthcare improvement: a cluster randomized trial. Implement Sci 2014;9:24.

6. Howlett JG, Chan M, Ezekowitz JA, et al. The Canadian Cardiovascular Society Heart Failure Companion: bridging guidelines to your practice. Can J Cardiol 2016;32:296-310.

7. Charmel PA, Frampton SB. Building the business case for patientcentered care. Healthc Financ Manage 2008;62:80-5.

8. The Strategy for Patient-Oriented Research (SPOR). Patient Engagement Framework 2014. Available at: http://www.impact.cihr-irsc.gc.ca/e/ 49232.html. Accessed June 10, 2018.

9. UHN Patient Partners Program. Available at: https://www.uhn.ca/ corporate/AboutUHN/Patient_Experience/Pages/patient_partners.aspx. Accessed June 10, 2018.

10. Health Quality Ontario (HQO). Ontario's Patient Engagement Framework 2017. Available at: http://www.hqontario.ca/Engaging-Patients/ Patient-Engagement-Framework. Accessed June 10, 2018.

11. Pandya-Wood R, Barron DS, Elliott J. A framework for public involvement at the design stage of NHS health and social care research: time to develop ethically conscious standards. Res Involv Engagem 2017;3:6.

12. INVOLVE. National Institute for Health Research. Public involvement in research: values and principles framework 2015. Available at: http:// www.invo.org.uk/posttypepublication/public-involvement-in-researchvaluesand-principles-framework/. Accessed June 10, 2018.

13. International Association for Public Participation (IAP2). IAP2 Public Participation Spectrum 2014. Available at: https://www.iap2.org/. Accessed June 10, 2018.

14. Centre of Excellence on Partnership with Patients and the Public (CEPPP). 2018. Available at: https://ceppp.ca/en/. Accessed June 10, 2018.

15. The Change Foundation (TCF). Should money come into it? A tool for deciding whether to pay patient-engagement participants 2015. Available at: https://www.changefoundation.ca/patient-compensationreport/. Accessed June 10, 2018.

16. Abelson J, Li K, Wilson G, et al. Supporting quality public and patient engagement in health system organizations: development and usability testing of the Public and Patient Engagement Evaluation Tool. Health Expect 2016;19:817-27.

\section{Supplementary Material}

To access the supplementary material accompanying this article, visit CJC Open at https://www.cjcopen.cal and at https://doi.org/10.1016/j.cjco.2019.01.002. 